\title{
Patient views on research use of clinical data without consent: Legal, but also acceptable?
}

\author{
Gesine Richter $^{1,2} \cdot$ Christoph Borzikowsky $^{3} \cdot$ Wolfgang Lieb $^{1} \cdot$ Stefan Schreiber ${ }^{4} \cdot$ Michael Krawczak $^{3} \cdot$ Alena Buyx $^{5}$
}

Received: 24 September 2018 / Revised: 27 November 2018 / Accepted: 25 December 2018 / Published online: 25 January 2019

(c) European Society of Human Genetics 2019

\begin{abstract}
The research exemption implemented in the new EU General Data Protection Regulation (EU-GDPR) gives member states leeway in determining whether patient consent is required for secondary data use in medical research. However, even though broad consent has become common in data-rich medical research in many EU countries, giving up consent altogether is likely to be controversial. The aim of this study was to examine whether abolishing consent for secondary data use would be acceptable to patients. A questionnaire study was conducted among 700 outpatients of a northern German university hospital to assess their attitude towards use of clinical data for scientific research without consent. There was both strong willingness to give broad consent for secondary data use (468 of 503 responders, 93.0\%) and strong approval of abolishing patient consent $(n=381,75.7 \%)$ among study participants. The willingness to give consent was moderately associated with approval of the respective stipulations by the EU-GDPR. In research settings where broad consent is widely accepted (e.g. university hospitals), abolishing consent for secondary research use of clinical data will likely be acceptable to a large majority of patients.
\end{abstract}

\section{Introduction}

The EU General Data Protection Regulation (Regulation 2016/679G EU, EU-GDPR) [1], which became enforceable law in all EU member states on 25 May 2018, will likely impact on both the governance of biobanks and the

Supplementary information The online version of this article (https:// doi.org/10.1038/s41431-019-0340-6) contains supplementary material, which is available to authorized users.

$\triangle$ Gesine Richter

gesine.richter@iem.uni-kiel.de

1 Institute of Epidemiology, Kiel University, University Hospital Schleswig-Holstein, Kiel, Germany

2 Institute of Experimental Medicine, Division of Biomedical Ethics, Kiel University, University Hospital Schleswig-Holstein, Kiel, Germany

3 Institute of Medical Informatics und Statistics, Kiel University, University Hospital Schleswig-Holstein, Kiel, Germany

4 Department of General Internal Medicine, University Hospital Schleswig-Holstein, Kiel, Germany

5 Institute of History and Ethics in Medicine, Technical University of Munich, Munich, Germany international sharing of data for medical research. Most EU member states are currently in the process of developing regulatory frameworks to translate the EU-GDPR into national law. One of the challenges in this process will be the implementation of the research exemption stipulated by the EU-GDPR, not least because member states are given certain leeway in this regard. While $\S 1$ of Article 9 of the EU-GDPR clearly states that processing of personal (i.e., identifiable, not anonymised) genetic, biometric or health data shall be prohibited, §2(j) specifies that this shall not be the case "if processing is necessary for archiving purposes in the public interest, scientific or historical research purposes or statistical purposes" [1]. The exemption is given in accordance with Article 89 of the EU-GDPR, which explicitly leaves room for national law to provide derogations under the requirement of safeguards [1].

The research exemption is highly contested among stakeholders and in the public. Recent regulatory plans in Austria, for example, made front-page news [2] and sparked both outrage and enthusiasm because they promised research use of national databanks without a need for explicit permission. In view of these and similar developments, it is high time to ascertain the attitudes of those primarily concerned (i.e., the data subjects), not only to guide the process of implementing new legal provisions by 
consulting public opinion, but also to facilitate patients' and participants' trust in biobanks and other forms of data-rich medical research. More explicitly, there is great need for a study of the extent to which participants in such projects would find research use of their data without consent acceptable, particularly in regions where this was previously not allowed.

Germany adapted the EU-GDPR in such a way that secondary data use for scientific research purposes without consent is allowed under certain conditions, and after balancing the interests of researchers and data subjects $(\$ 27)$ [3]. Whilst other member states might move into different directions, Germany and Austria (\$25) [4] thus chose to pursue broad implementation of the research exemption. The aim of our study was to find out whether the provisions made in Germany are acceptable to the individuals concerned. Even at a time when broad consent has started to become the ethical and regulatory standard of data-rich medical research and biobanking in many countries [5, 6], outright abolition of consent is likely to be controversial, at least in countries with strict previous consent regulations. Those who have already argued against "blanket" consent in the past will surely object any policy implying that patients receive no information at all anymore about the intended research use of their data [7].

\section{Materials and methods}

After approval of the study by the local ethics committee, a total of 700 adult patients were approached in waiting rooms of the Comprehensive Center for Inflammation Medicine (CCIM) in Kiel, Germany, between March 2018 and May 2018, and were asked for participation in the present study. The CCIM is an outpatient clinic for inflammatory conditions at the University Hospital Schleswig-Holstein (UKSH), the largest health-care provider in the northern-most federal state of Germany and the second biggest university hospital in Germany $(150,000$ patients per year). At UKSH Campus Kiel, healthcareembedded biobanking was implemented in 2017 under a new broad consent policy covering both left-over biomaterial and clinical data [6]. The CCIM patient population can be assumed to reflect the socio-demographic structure of all outpatients at UKSH Campus Kiel. All patients received an informational brochure and the broad consent form at the time of admission. Our previous project [6] to evaluate the acceptance and understanding of these documents revealed that the willingness to give broad consent for healthcare-embedded biobanking is high at UKSH Campus Kiel $(>90 \%)$. In the present study, carried out under essentially the same conditions, participants were asked to fill-out a questionnaire designed to evaluate their attitude towards the use of data and left-over biomaterial for research purposes without consent. Patients had the opportunity to discuss the documents and any emerging questions with trained CCIM staff.

\section{Questionnaire}

A questionnaire was developed specifically for the present study and pre-tested in order to determine its appropriate length and to evaluate its general comprehensibility (see annex). The questionnaire comprised 14 items, including 10 Likert-scaled items, two statement items and two socio-demographic questions. Depending upon whether a participant gave consent or not, the first statement item assessed the individual reasons for their choice. The second statement item assessed why a participant agreed, or did not agree, to the consent-related EU-GDPR provisions. The questionnaire consisted of three parts: (a) motivation to give or not give broad consent, (b) attitude towards research without consent and (c) basic human values (see supplementary material).

(a) The first section was devoted to an assessment of the motivation to either give broad consent (10 statement items M01-M10, several responses allowed, derived based upon $[6,8]$ ) or refuse broad consent (eight statement items, several responses allowed). Similar to the attitude items, participants indicated agreement to a statement by checking a box.

(b) The second section of the questionnaire contained a short description of the EU-GDPR, including information about its implementation in Germany. It was explicitly stated that German law allows data processing for scientific research without consent given that no patient interests are violated, sufficient measures of data protection are taken, and that the research goals are of significant importance (§27) [3]. Participants were asked for their attitude towards this regulation (four pro and four contra statements, respectively; more than one response possible), with agreement to a given statement indicated by checking a box. Participants who selected both pro and contra statements ( $n=14)$ were excluded from further analyses. The final data set $(n=503)$ included only participants who clearly agreed $(n=381)$ or disagreed $(n=122)$ with the regulation.

(c) The third section served to measure the participants' general social attitude using the German version of the Short Schwartz's Value Survey (SSVS) [9]. This survey is a well-established tool $[10,11]$ and has been translated and validated in German [12]. The underlying theory postulates the existence of 10 basic human values (power, achievement, hedonism, stimulation, self-direction, universalism, benevolence, tradition, conformity, security) that can be distinguished across most human societies and that shape behavior and decision-making of human individuals [13]. 
From these values, higher-order types can be formed recognizing closer relationships between particular values. Individuals can thus be stratified into groups for whom certain value combinations are of particular importance [13]. In our project, we drew upon the higher-order types originally suggested by Schwartz [13], namely SelfTranscendence (universalism, benevolence), Conservation (security, conformity, tradition), Self-Enhancement (achievement, power), and Openness to Change (selfdirection, stimulation, hedonism). The SSVS [9] adds a short definition to each value and provides answering options on a six-graded Likert scale (from 1: not important at all to 6: very important).

\section{Statistics}

Descriptive statistics were calculated using IBM SPSS Statistics for Windows [14]. In the case of participants' attitude and motivation (parts 1 and 3 of the questionnaire), absolute and relative frequencies of agreement were determined for each statement item. Items of the SSVS (part 2 of the questionnaire) were aggregated into the four higher-order value types of Self-Transcendence, Conservation, SelfEnhancement, and Openness to Change. Mean and standard error of the mean of the participant-specific average Likert ratings of the subsumed SSVS items were calculated for each higher-order value type and the means compared between subgroups using a two-sample $t$-test for independent samples. Fisher's exact test was used to compare categorical variables between subgroups. Proportions were compared to theoretical expectations using a binomial test. Correlations between dichotomous variables were quantified by means of Cohen's kappa. $p$ values $<0.05$ were regarded as statistically significant.

\section{Results}

The project, which was carried out as a delivery-andcollection questionnaire study, achieved a high level of participation. Of 700 delivered questionnaires, $585(83.6 \%)$ were returned and $503(86.0 \%)$ were sufficiently complete for the data to be useable for analysis.

Whilst significantly more women $(n=327,65.0 \%)$ than men $(n=176,35.0 \%$; binomial test $p<0.01)$ participated in the study, the sex-specific age distributions were found to be similar (Fisher's exact test $p>0.05$; Table 1). Moreover, in terms of age and level of education, the study sample was well representative of the general German population (Table 1).

\section{Acceptance of broad consent and motivation}

The willingness to give broad consent for healthcareembedded biobanking was very high $(n=468,93.0 \%)$ and the participants' motivation to actually consent (motivational items M01-M10; Table 2) was found to be consistent with our previous study [6]. Most participants who

Table 1 Demographic characteristics of study participants and acceptance of broad consent $(n=503)$

\begin{tabular}{|c|c|c|c|c|}
\hline$\overline{\text { Age (years) }}$ & Male $(\%)^{\mathrm{a}}$ & Acceptance of broad consent $(\%)^{\mathrm{b}}$ & Female $(\%)^{\mathrm{a}}$ & Acceptance of broad consent $(\%)^{b}$ \\
\hline $18-30$ & $19(10.8)$ & $15(79.0)$ & $56(17.1)$ & $49(87.5)$ \\
\hline $31-45$ & $48(27.3)$ & $44(91.7)$ & $78(23.9)$ & $73(93.6)$ \\
\hline $46-60$ & $70(39.8)$ & $64(91.4)$ & $127(38.8)$ & $121(95.3)$ \\
\hline $61-75$ & $33(18.8)$ & $31(93.9)$ & $57(17.4)$ & $57(100.0)$ \\
\hline 76-90 & $6(3.4)$ & $6(100.0)$ & $9(2.8)$ & $8(88.9)$ \\
\hline Educational level & $\operatorname{Male}(\%)^{\mathrm{c}}$ & Acceptance of broad consent $(\%)^{d}$ & Female $(\%)^{\mathrm{c}}$ & Acceptance of broad consent $(\%)^{d}$ \\
\hline Elementary/primary school & $8(4.5)$ & $8(5.0)$ & $20(6.1)$ & $19(6.2)$ \\
\hline Secondary school & $83(47.2)$ & $76(47.5)$ & $178(54.4)$ & $167(54.2)$ \\
\hline High school & $38(21.6)$ & $34(21.3)$ & $73(22.3)$ & $70(22.7)$ \\
\hline University degree & $38(21.6)$ & $35(21.9)$ & $32(9.8)$ & $30(9.7)$ \\
\hline Other graduation & $9(5.1)$ & $7(4.4)$ & $24(7.3)$ & $22(7.1)$ \\
\hline Total $(\%)^{\mathrm{e}}$ & $176(35.0)$ & $160(90.9)$ & $327(65.0)$ & $308(94.2)$ \\
\hline
\end{tabular}

${ }^{a}$ Sex-specific percentage of participants in age group (reference: total number of males/females)

${ }^{b}$ Acceptance of broad consent within sex-specific age group (reference: total number of participants in sex-specific age group)

${ }^{\mathrm{c}} \mathrm{Sex}$-specific percentage of participants in education level (reference: total number of males/females)

${ }^{\mathrm{d} A c c e p t a n c e}$ of broad consent within sex-specific education level (reference: total number of participants in sex-specific education level group)

${ }^{\mathrm{e}}$ Overall percentage of participants (reference: total number of participants) 
Table 2 Motivation of participants to consent $(n=468$, multiple responses possible)

\begin{tabular}{|c|c|c|c|}
\hline Item no. & Concept & Motivational item & Number $(\%)$ \\
\hline M01 & Altruism & Support of research in general & $403(86.1)$ \\
\hline M02 & & Helping all future patients & $315(67.3)$ \\
\hline M03 & Reciprocity & $\begin{array}{l}\text { Returning own benefit from } \\
\text { research }\end{array}$ & $339(72.4)$ \\
\hline M04 & Solidarity & $\begin{array}{l}\text { Helping future patients with same } \\
\text { disease }\end{array}$ & $328(70.1)$ \\
\hline M05 & & $\begin{array}{l}\text { Feeling connected with future } \\
\text { patients }\end{array}$ & $189(40.4)$ \\
\hline M06 & Gratitude & Gratitude towards doctors & $214(45.7)$ \\
\hline M07 & Other & Hope for personal benefit & $153(32.7)$ \\
\hline M08 & & Knowing of others who consented & $16(3.4)$ \\
\hline M09 & & $\begin{array}{l}\text { Worry about disadvantages when } \\
\text { not consenting }\end{array}$ & $4(0.9)$ \\
\hline M10 & & No specific reasons & $41(8.8)$ \\
\hline
\end{tabular}

Table 3 Motivation of participants not to consent $(n=35$, multiple responses possible)

\begin{tabular}{lc}
\hline Motivational item & Number $(\%)$ \\
\hline Worries about data security & $14(40.0)$ \\
Wanting to know type of research & $13(37.1)$ \\
Wanting to know who does research & $12(34.3)$ \\
Denial of research on other than own disease & $5(14.3)$ \\
No personal benefit expected from consenting & $4(11.4)$ \\
Insufficient personal benefit from research so far & $3(8.6)$ \\
Worries about disadvantages when consenting & $0(0.0)$ \\
No specific reasons & $7(20.0)$ \\
\hline
\end{tabular}

consented did so mainly for pro-social reasons, including altruism (M01, M02), reciprocity (M03) solidarity (M04, M05), and gratitude (M06) (terms defined according to Prainsack and Buyx [8]). Self-interest (M07) or the experience of others (M08) did not play a major role, and only very few participants worried about disadvantages if they did not consent (M09) or had no specific reason for consenting at all (M10).

A small minority of participants refused to give broad consent $(n=35,7.0 \%)$ mainly owing to worries about data security ( $n=14,40.0 \%)$, an explicit wish to know which type of research will be undertaken with their data $(n=13$, $37.1 \%)$, and by whom $(n=12,34.3 \%$; Table 3$)$.

\section{Attitude towards research without consent}

The majority of participants $(n=381,75.7 \%)$ approved the EU-GDPR stipulation that, under certain conditions, patients no longer would have to consent to the use of their personal data for scientific research. Reciprocity seemed to be the main motivation to accept such a policy. Thus, 233 participants $(61.2 \%)$ agreed that the regulation was selfevident, owing to the general benefit arising from medical research. Some participants who approved the new regulation, however, would prefer some restrictions imposed upon the use of their data, including mandatory review of the research plan by a dedicated committee $(n=95,24.9 \%)$, or by limiting the research to certain areas $(n=89,23.4 \%)$.

The main reason to oppose the new regulation $(n=122$, $24.3 \%)$ was a lack of control over the type $(n=89,73.0 \%)$ and over the conditions $(n=72,59.0 \%)$ of use. A moderately positive correlation was observed between the willingness to give broad consent for healthcare-embedded biobanking and the approval of an abolition of patient consent (Cohen's kappa: 0.24, Fisher's exact test $p<0.001$ ). Whilst the vast majority of participants who gave broad consent approved the regulation $(n=371,79.3 \%)$ the majority of those who denied broad consent objected the regulation $(n=25,71.4 \%)$.

\section{Human values and attitude towards research without consent}

The predominant SSVS values in our study would be subsumed under higher-order types Self-Transcendence (mean answer \pm standard error of the mean: $5.32 \pm 0.03$ ), Conservation ( $4.59 \pm 0.04)$, and Openness to Change (4.49 \pm 0.04). Self-Enhancement, which subsumes achievement and power, was comparatively rare $(3.53 \pm 0.04)$.

The theory of SSVS human values assumes opposition between conflicting values [13]. In our study, the most important value overall, namely Self-Transcendence, was found to be equally relevant to participants who approved or disapproved the abolition of patient consent (5.33 \pm 0.04 vs. $5.29 \pm 0.07$, Table 4). However, a consistent difference of

Table 4 Higher-order types of human values and attitude towards abolition of patient consent $(n=503)$

\begin{tabular}{|c|c|c|c|c|c|}
\hline \multirow[t]{3}{*}{ Higher-order type value } & \multicolumn{4}{|c|}{$\begin{array}{l}\text { Attitude towards abolition of } \\
\text { patient consent }\end{array}$} & \multirow[t]{3}{*}{$p$} \\
\hline & \multicolumn{2}{|c|}{$\begin{array}{l}\text { Approval }(n= \\
381)\end{array}$} & \multicolumn{2}{|c|}{$\begin{array}{l}\text { Disapproval }(n \\
=122)\end{array}$} & \\
\hline & Mean $^{\mathrm{a}}$ & SEM & Mean $^{\mathrm{a}}$ & SEM & \\
\hline Self-transcendence & 5.33 & 0.04 & 5.29 & 0.07 & 0.63 \\
\hline Conservation & 4.62 & 0.04 & 4.47 & 0.07 & 0.08 \\
\hline Self-enhancement & 3.51 & 0.05 & 3.59 & 0.09 & 0.40 \\
\hline Openness to change & 4.45 & 0.04 & 4.62 & 0.08 & 0.06 \\
\hline
\end{tabular}

SEM: standard error of the mean, $p$ : two-sided $p$-value from a Student's $t$-test

${ }^{\mathrm{a}}$ Mean answer on a six-graded Likert scale (from 1: not important at all to 6: very important) 
borderline statistical significance was observed for higherorder types Openness to Change and Conservation, which are assumed to be opposing [13]. More specifically, study participants who approved abolition of patient consent were more conservative $(4.62 \pm 0.04$ vs. $4.47 \pm 0.07$, two sample $t$-test $p=0.08)$ and less open to change $(4.45 \pm 0.04$ vs. $4.62 \pm 0.08$, two sample $t$-test $p=0.06$ ) than those who disapproved.

\section{Discussion}

In times when medicine becomes more and more data-driven, there is growing interest in healthcare-embedded biobanking and the secondary use of personal clinical data for research. If done in scientifically valid fashion, making use of such existing resources can reduce the costs of research, increase sample sizes, and hence improve study efficiency [15-17]. Consequently, animated discussions on the appropriate use and access of such data are ongoing. The regulatory and governance issues involved, in particular, have been hotly debated for the last decade, and many different approaches have been taken to deal with them, not only across Europe, but globally [18, 19]. With the recent coming into force of the EU-GDPR, however, a greater degree of legal harmonization is expected to result between EU member states, including the specific data protection requirements arising in medical research [20]. At the same time, it has become clear that the EU-GDPR leaves ample room for national regulation of whether personal medical data can be used for research without consent [21, 22].

Currently, EU member states are in the process of developing national regulatory frameworks to implement the EU-GDPR. Germany has already done so and, as part of an update of its national data privacy legislation, now newly allows secondary data use without consent for scientific research after appropriate weighing of interests. As a matter of course, this exemption is granted only under the condition that sufficient standards of data protection are adhered to. While some stakeholders are highly critical of research without explicit consent [23], others have argued that citizens are under an ethical obligation to share their health information for research purposes [19, 24, 25]. In order to add empirical evidence to this discussion, we studied the attitudes towards the regulation in question of those primarily concerned, namely patients in clinical settings. We were particularly interested in the patients' view on this issue because even broad consent was only recently accepted and adopted by German biobanks [6, 26, 27].

We made two main observations. First, willingness to give broad consent was very high in our study $(n=468$, 93.0\%), confirming our own previous findings on patients' attitude towards broad consent for healthcare-embedded biobanking [6], as well as studies of other forms of biobanking (e.g. ref. [28]). The main motivations to give broad consent were prosocial (altruism, reciprocity, and solidarity). A small minority of patients worried about data security $(n=14,2.8 \%)$ or insisted upon receiving more information about research purposes and the researchers involved $(n=13,2.6 \%)$, and therefore did not give broad consent. Hence, we may conclude that patients generally accept unlimited storage and broad use of their samples and data for medical research. Our data suggest that a high level of pro-social factors and trust motivate this attitude, in line with previous findings $[6,29,30]$.

Our second observation relates to the original aim of the study. There was surprisingly strong approval $(n=381$, $75.7 \%$ ) of the new legal regulation that allows research with clinical data without patient consent under certain conditions. Furthermore, the approval was moderately associated with a positive attitude towards broad consent. In summary, these results thus indicate that, in research settings where broad consent is already widely accepted (e.g. university hospitals), abolishing consent for secondary research use of clinical data may not face much resistance, at least not by patients.

A clear majority of the participants $(>75 \%)$ in our study supported the new regulation. The reasons given reflected feelings of reciprocity, with participants being aware that everybody can potentially benefit from data-driven medical research. However, there is still a minority of roughly $25 \%$ of participants who do not accept research without consent. They oppose the regulation mainly because they would no longer be able to decide the use of their data and lack control over the research done.

These findings highlight that research without consent causes different reactions, which we found to be associated with different values. Patients in favor of the new regulation were more conservative than those disapproving, as judged by the human values measured according to Schwartz [13]. This might seem surprising because individuals with more conservative values may be expected to generally object to changes of the status quo. However, willingness to follow rules and regulations might be higher in this group, thus explaining why they were willing to go along with a change that was determined by legislators. Participants appeared to be happy to delegate the decision regarding the use of their data to researchers or healthcare institutions, which could also indicate that the more conservative group had higher trust in those with (perceived) professional or institutional authority. By contrast, those opposing research without consent were characterized by more openness to change, which may also seem surprising at first glance. However, the inclination to follow rules could have been generally lower in this group. Moreover, openness to change may also be accompanied by a greater desire to retain 
self-determination, thereby explaining the frequently expressed wish to keep control over own data in this group.

Overall, arguments can be found for both positions in question, and it is thus not surprising that they both occurred in our study population. From an ethical point of view, and to properly account for the diversity of values in societies, the prominent desire for self-determination observed here cannot be ignored even if the majority of participants were accepting the new regulation. Thus, researchers may well conduct future projects according to the new regulation, knowing that they are supported by three quarters of patients, but policy-makers should continue to offer the dissenting group a choice that allows preserving their autonomy and self-determination, e.g. by the introduction of opt-out mechanisms prior to any data collection [31].

\section{Limitations}

Even although our sample was large and a high response rate was achieved, our results may not be directly transferable to other clinical or cultural backgrounds. This notwithstanding, we believe that the qualitative results of our study will hold true for similar settings in other EU member states, where forms of consent for data-driven research are currently being revised in the light of the EU-GDPR. Second, our sample was representative of the overall German population, with the exception of gender; there were significantly more women than men in our sample.

Women have been found to exhibit higher pro-social motivation in health care contexts that require donations (e.g. ref. [32]).Thus, the responses regarding the motivation to give broad consent or to accept research without consent in our study may have been skewed in this direction as well. However, our research indicated that conservatism, rulefollowing, and self-determination also play a role in the assessment of consent abolition. Previous results on possible gender differences regarding these motivational concepts are mixed $[33,34]$. More research is thus necessary to discern whether gender and other potential factors influence decision-making regarding data-driven research and acceptance of policy changes.

\section{Conclusion}

Our study shows that research with clinical data without patient consent, recently made possible through the EUGDPR, seems to be acceptable to a majority of patients in Germany. However, with biobanking and data-rich medicine being dependent upon sustained public support and trust, those who object to this policy (roughly one quarter in our study) should not be disregarded. Introducing opt-out mechanisms before collection could ensure that the entire patient population continues supporting large-scale data research. In addition, increased transparency regarding data protection and governance, as well as regarding research objectives would help to ensure that the wide current approval of data use without consent remains stable in the long term.

Acknowledgements The authors gratefully acknowledge the kind support by all academic and non-academic staff of the Comprehensive Centre for Inflammation Medicine (CCIM), University Hospital Schleswig-Holstein Campus Kiel, and thank all patients for their participation.

\section{Compliance with ethical standards}

Conflict of interest The authors declare no conflict of interest.

Publisher's note: Springer Nature remains neutral with regard to jurisdictional claims in published maps and institutional affiliations.

\section{References}

1. Regulation $2016 / 679$ of the European parliament and the Council of 27 April 2016 on the protection of natural persons with regard to the processing of personal data and on the free movement of such data, and repealing Directive 95/46/EC (General Data Protection Regulation). https://ec.europa.eu/info/law/law-topic/dataprotection/data-protection-eu_en. Accessed 10 Sept 2018.

2. Page Der Standard, 2018. https://derstandard.at/2000077710061/ Regierung-will-Daten-der-Buerger-fuer-Forschung-freigeben. Accessed 12 Sept 2018.

3. Gesetz zur Anpassung des Datenschutzrechts an die Verordnung (EU) 2016/679 und zur Umsetzung der Richtlinie (EU) 2016/680 (Datenschutz-Anpassungs- und Umsetzunggesetz EU-DSAnpUG-EU) (Law on the adaptation of data protection law to Regulation (EU) 2016/679 and the implementation of Directive (EU) 2016/680 (Data Protection Adaptation and Implementation Act EU), 30 Juni 2017, Bundesgesetzblatt 5.Juli 2017.

4. Bundesgesetz, mit dem das Bundes-Verfassungsgesetz geändert, das Datenschutzgesetz erlassen und das Datenschutzgesetz 2000 aufgehoben wird (Datenschutz-Anpassungsgesetz 2018) (Federal Act amending the Federal Constitutional Law, enacting the Data Protection Act and repealing the Data Protection Act 2000), 31.07.2017, BGB1. I Nr. 120/2017.

5. Grady C, Eckstein L, Berkman B, et al. Broad consent for research with biological samples: workshop conclusions. Am J Bioeth. 2015;15:34-42.

6. Richter G, Krawczak M, Lieb W, Wolff L, Buyx A. Broad consent for health care-embedded biobanking: understanding and reasons to donate in a large patient sample. Genet Med. 2018;20:76-82.

7. Bullock E, Widdows $\mathrm{H}$. Reconsidering consent and biobanking. In: Lenk C, Sándor J, Gordijn B, editors. Biobanks and tissue research-the public, the patient and the regulation. Heidelberg, Germany: Springer; 2011. p. 111-26.

8. Prainsack B, Buyx A. Solidarity in biomedicine and beyond. Cambridge, UK: Cambridge University Press; 2017.

9. Boer D. Short Schwartz's Value Survey in German (SSVS-G). 2013. https://www.uni-koblenz-landau.de/de/koblenz/fb1/institutpsychologie/abteilungen/sozial\%20und\%20organisa tionspsychologie/SSVS-G. Accessed 10 Sept 2018. 
10. Yeganeh H, Su Z, Sauers D. The applicability of widely-employed frameworks in cross-cultural management research. J Acad Res Econ 2009;1:13-32.

11. Spini D. Measurement equivalence of 10 value types from the Schwartz value survey across 21 countries. J Cross Psychol. 2003;34:23.

12. Boer D. SSVS-G. Short Schwartz's Value Survey-German. In: Kemper C, Zenger M, Brähler E, editors. Psychologische und sozialwissenschaftliche Kurzskalen. Berlin, Germany: Medizinisch Wissenschaftliche Verlagsgesellschaft; 2014. p. 299-302.

13. Schwartz SH, Cieciuch J, Vecchione M, et al. Refining the theory of basic individual values. J Pers Soc Psychol. 2012;103:663-88.

14. IBM [IBM SPSS Statistics]. Release 22.0.0.2 for windows, Armonk, NY: IBM.

15. Kaye J. Embedding biobanks in a changing context. In: Kaye J, Gibbons SMC, Heeney C, Parker M, Smart A, editors. Governing Biobanks: understanding the interplay between law and practice. Oxford, UK: Hart Publishing; 2012. p. 30-51.

16. Tassé AM. A comparative analysis of the legal and bioethical frameworks governing the secondary use of data for research purposes. Biopreserv Biobank. 2016;14:207-16.

17. Boulos D, Morand E, Foo M, et al. Acceptability of opt-out consent in a hospital patient population. Intern Med J. 2018;48:84-87.

18. Lipworth W, Kerridge I. Consent to biobank research: facing up to the challenge of globalization. Am J Bioeth. 2015;15:58-59.

19. Kaye J, Terry ST, Juengst E, et al. Including all voices in international datasharing governance. Hum Genom. 2018;12:13.

20. Kaye J, Briceño ML, Curren L, et al. Consent for Biobanking: the legal frameworks of countries in the BioSHaRE-EU project. Biopreserv Biobank. 2016;14:195-200.

21. Timmers M, Van Veen EB, Maas AIR, Kompanje EJO. Will the EU Data Protection Regulation 2016/679 inhibit critical care research? Med Law Rev 2018; fwy023, https://doi.org/10.1093/ medlaw/fwy023.

22. Shabani M, Borry P. Rules for processing genetic data for research purposes in view of the new EU General Data Protection Regulation. Eur J Hum Genet. 2018;26:149-56.
23. Gelinas L, Wertheimer A, Miller FG. When and why is research without consent permissible? Hastings Cent Report. 2016;46:9.

24. Taichman DB, Sahni P, Pinborg A, et al. Data sharing statements for clinical trials - a requirement of the International Committee of Medical. J Ed N Engl J Med. 2017;376:2277-9.

25. Ballantyne A, Schaefer GO. Consent and the ethical duty to participate in health data research. J Med Ethics. 2018;44: 392-6.

26. Strech D, Bein S, Brumhard M, et al. A template for broad consent in biobank research. Results and explanation of an evidence and consensus-based development process. Eur J Med Genet. 2016;59:295-309.

27. Jacobs G, Wolf A, Krawczak M, Lieb W. Biobanks in the era of digital medicine. Clin Pharmacol Ther. 2018;103:761-2.

28. Platt J, Bollinger J, Dvoskin R, Kardia SL, Kaufman D. Public preferences regarding informed consent models for participation in population-based genomic research. Genet Med. 2014;16:11-8.

29. Kettis-Lindblad A, Ring L, Viberth E, Hansson MG. Genetic research and donation of tissue samples to biobanks. What do potential sample donors in the Swedish general public think? Eur J Public Health. 2005;16:433-40.

30. Dixon-Woods M, Kocman D, Brewster L, Willars J, Laurie G, Tarran C. A qualitative study of participants'views on re-consent in a longitudinal biobank. BMC Med Ethics. 2017;18:22.

31. Giesbertz NA, Bredenoord AL, van Delden JJ. Inclusion of residual tissue in biobanks: opt-in or opt-out? PLoS Biol. 2012;10: e1001373.

32. Decker O, Winter M, Brähler E, Beutel M. Between commodification and altruism: gender imbalance and attitudes towards organ donation. A representative survey of the German community. J Gend Stud. 2008;17:251-5.

33. Inglehart RF, Norris P. Rising tide: gender equality and cultural change around the world. New York, USA: Cambridge University Press; 2003.

34. Yeganeh H, May D. Cultural values and gender gap: a crossnational analysis. Gend Manag: Int J. 2011;26:106-21. 